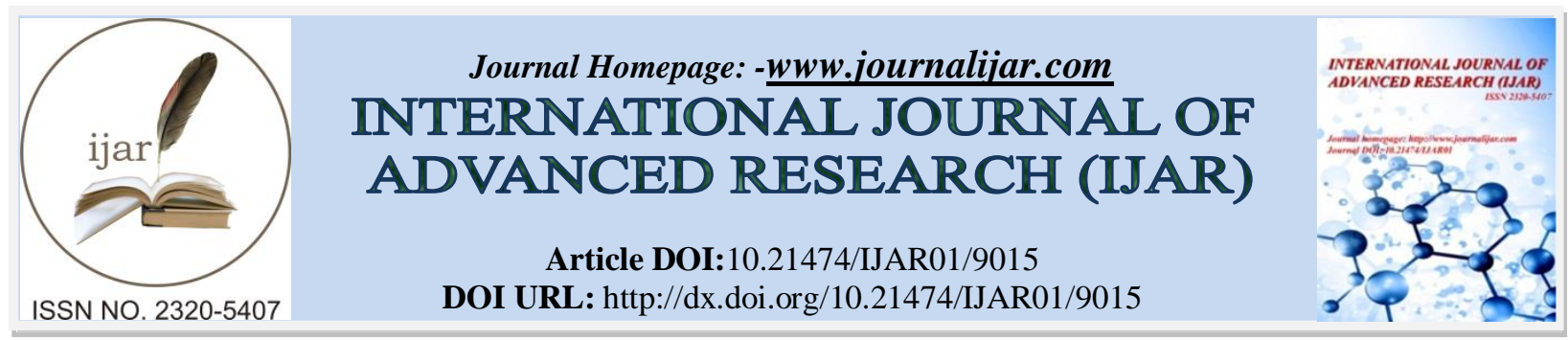

RESEARCH ARTICLE

\title{
UTILIZATION OF BUCCAL FAT PAD IN ORAL SUB MUCOUS FIBROSIS-A CASE REPORT.
}

\author{
Abin Varghese*, Kamaraj Loganathan*, Senthil Kumar G*, Nimal Ram Gandhi*, Tina Varghese**. \\ *Department of Oral and Maxillofacial Surgery,Penang International Dental College,Malaysia. \\ **Department of Periodontolgy, MBDC, Kerala,India .
}

\section{Manuscript Info}

\section{Manuscript History}

Received: 04 March 2019

Final Accepted: 06 April 2019

Published: May 2019

Key words:-

Oral submucous fibrosis,,Buccal Fat Pad, Oropharyngeal, esophageal mucosa.

\begin{abstract}
Oral submucous fibrosis is a potentially malignant disorder, having its highest incidence in the south east asian population. It affects oral, oropharyngeal, and at times esophageal mucosa, producing clinical signs and symptoms including excessive salivation, limited mouth opening, burning sensation, absent gustatory sensation, difficulty in chewing and swallowing, narrowing of the eustachian tube causing disturbance in hearing too.There has been reported a high risk of malignant transformation associated with the same. Buccal Fat Pad has been reported to be succesful in the management of the same. We report a case where buccal pad of fat has been successfully used in the management of oral submucous fibrosis.
\end{abstract}

Copy Right, IJAR, 2019,. All rights reserved.

\section{Introduction:-}

Pindborg (1966) defined OSMF as, "an insidious, chronic disease affecting any part of the oral cavity and sometimes the pharynx. Although occasionally preceded by and/or associated with vesicle formation, it is always associated with juxta-epithelial inflammatory reaction followed by fibroelastic change of the lamina propria, with epithelial atrophy leading to stiffness of the oral mucosa and causing trismus and inability to eat ${ }^{1}$.The highest incidence is found in South India, with an overall prevalence rate of $2.5 \%$ in various states of the country ${ }^{2}$. It affects oral, oropharyngeal, and at times esophageal mucosa ${ }^{3}$.Clinical signs and symptoms include excessive salivation, limited mouth opening, burning sensation, absent gustatory sensation, etc. which subsequently results to difficulty in chewing and swallowing. The condition can cause narrowing of the eustachian tube causing disturbance in hearing too $^{3}$. Esophageal involvement can lead to progressive dysphagia ${ }^{3}$.It has also been reported with an increased risk of malignancy and hence it is considered as one of pre-malignant condition ${ }^{4}$.

The management of the condition depends upon the stage of involvement, as in the early stages quitingthe habit is sufficient. The medical management includes multiphase injections of hyaluronidase, hydrocortisone, placental extract, triamcinolone plus vitamin, and iron supplements. Surgical management is the treatment of choice in cases with marked limitation of mouth opening, usually stages III and IV ${ }^{5}$.The following surgical modalities have been used: release of fibrous bands and covering of the raw areas with split thickness skin grafting, bilateral nasolabial flaps, palatal island flaps, tongue flaps, temporalis myotomy, and coronoidectomy ${ }^{6}$.

The buccal fat pad is an anatomically rounded and biconvex structure that is of great importance in the facial contour $^{7}$. The buccal fat pad is mainly used to cover defects in the posterior maxilla, the buccal region, the hard 
palate, the soft palate, and the retromolar and pterygomandibular regions after tumor resections and oroantral communications after tooth extractions ${ }^{8,9}$. Its use as a pedicle graft for oral reconstruction was first reported byEgyedi in $1977^{10}$. In 1983, Neder ${ }^{11}$ reported the use of the BFP as a free graft for intra-oral defects.It is an adipose tissue surrounded by a thin capsule and located inside both masticatory spaces in the oromaxillofacial region ${ }^{12}$.

The BFP ( Figure 1) has a central body with four extensions: pterygopalatine, temporal, pterygoid,and buccal ${ }^{13}$. The central body and buccal extension account for approximately 50\% of the BFP and are the most clinically significant portions ${ }^{14}$. The blood supply of the BFP is from three sources: the maxillary, superficial temporal and facial artery ${ }^{9}$. The physiology of buccal fat tissue is not totally clarified. However, it is thought that the buccal fat pad is closely associated with the muscles of mastication. It plays an important role in masticatory function especially in the infant during suckling. Its size diminishes as the infant grows with the accompanying growth of the surrounding facial structures $^{15}$. In the adult, the BFP enhances inter-muscular motion and resembles orbital fat in appearance and function $^{16}$.

\section{Case Report:}

A 45 year old male patient came to Vairam Hospital, Namakal with difficulty in mouth opening since 2 months ( Figure 2). The history revealed that the condition was gradual and progressive and was associated with occassional burning sensation which gradually became continous. Initially the burning sensation was present on taking spicy food. Now a days the condition is present on taking other food too. Even though the patient sought treatment in a nearby hospital, he was unable to continue the same. The rest of the history is non-contributory except he is a chronic pan chewer, since 10 years with a frequency of 4-6 times a day,chews and spits off.

Intra oral examination on inspection revealed the presence of resticted mouth opening, pallor, reduced movement of the soft palate,deviated uvula (Figure 3 and figure 4). On palpation there was loss of resiliency of the buccal mucosa, presence of vertical bands. The condition was provisionally diagnosed as stage 111 osmf. The differential diagnosis was anemia and scleroderma.A wide excision of the lesion followed by reconstruction with buccal pad of fat was done. Bilaterally fibrotic bands was relieved and closure achieved by buccal pad fat ( Figure 5 and figure 6). Patient was followed up for six months, there wasexcellent results ( Figure 7).

\section{Discussion:-}

Oral sub mucous fibrosis is a chronic, progressive, and irreversible disease of unknown aetiology ${ }^{3}$. There is an overall prevalence of up to $0-4 \%$ in places at Kerala ${ }^{1}$.The pathogenesis of the condition is unknown with multifactorial etiology including areca nut chewing, ingestion of chilies, genetic andimmunologic processes, nutritional deficiencies and other factors ${ }^{3}$. There is female predilection ${ }^{17}$ and the mean age has been reported from 11-60 years ${ }^{3}$. According to Pindborg in 1989 OSF is clinically divided into 3 stages $^{1}$. Stage 1: Stomatitis includes erythematous mucosa, vesicles, mucosal ulcers, melanotic mucosal pigmentation, and mucosal petechia.Stage 2: Fibrosis,trismus, blanched appearance ,reduced mobility of the soft palate, stiffness of the tongue, shrunken bud like uvula.Stage 3: OSMF associated with precancerous lesion like leukoplakia, speech and hearing deficits may occur because of involvement of the tongue and the eustachian tubes.

Non surgical management of these patients includes discontinuation of the habit, abstain from spicy foods. Medicinal measures includeuse of local steroids, placental extracts, hyaluronidase injections singly or in combination with oral anti-oxidant supplements along with oral physiotherapy exercises. Surgical management measures include excision of fibrous bands followed by coverage a with skin grafts, collagen or other dressing materials like, buccal pad of fat, local flaps, vascularized flaps, with or without coronoidectomy and post-operative active jaw physiotherapy ${ }^{18}$.

In addition to the various advantages, there are numerous disadvantages associated with the use of various flaps. The simple release of fibrosis and skin grafting can cause scarring and graft contraction resulting in recurrence ${ }^{19}$, the usage of flaps such as a buccal advancement flap, a palatal pedicled flap, or double layered closure flaps can produce large denuded areas, decrease of vestibular sulcus and cannot be used to close large defects ${ }^{20}$.The nasolabial flaps can cause esthetically compromising extraoral scar ${ }^{21}$. The island palatal mucoperiosteal flap, is possible only where the palatal mucosa is free of $\mathrm{OSMF}^{22}$. Bilateral palatal flaps leave a large raw area on the palatal bone. Other flaps like bilateral radial artery forearm free flaps ${ }^{23}$, the bi-paddled radial forearm flap ${ }^{24}$ require microvascular expertise; more over the flaps are hairy and require debulking procedures. 
In our case followed by excision of the fibrous bands, we used the buccal fat pat. The buccal fat pad (BFP) is an encapsulated, rounded, biconvex specialized fatty tissue which is distinct from subcutaneous fat $^{7} \cdot \mathrm{BFP}$ helps in the closure of oro-antral communications, reconstruction of secondary to maxillary cyst defects and intra-oral tumor resections ${ }^{25}$. Size limitations of BFP must be known in order to provide successful outcome. The closure of larger defects produce flap necrosis,flap dehiscence or creating a new fistula as reported by Rapidis et al ${ }^{25}$ and Granizo et $\mathrm{al}^{26}$. Although the ideal defects to be reconstructed with a BFP are the maxillary defects, due to their close anatomical location, it can be applied in areas ranging from the mouth angle to the retromolartrigone and palate ${ }^{14}$. The advantages of BFP include ease harvesting, simplicity, versatility, and low rate of complication as well as quick surgical technique ${ }^{25,16}$ To date, reported complications with the use of the BFP flap are hematoma, partial necrosis, excessive scarring, infection or facial nerve injury ${ }^{27 .}$

\section{Conclusion:-}

The easy mobilization of the buccal fat pad and its excellent blood supply and minimal donor site morbidity make it an ideal flap. It can be very useful in older patients to reconstruct defects quickly under local anesthesia.

Acknowledgment:-This is to express my gratitude towards Professor Dr K Thangavelu,Oral and Maxillofical surgeon, Variam Hospital, Namakal, for the guidance and support.

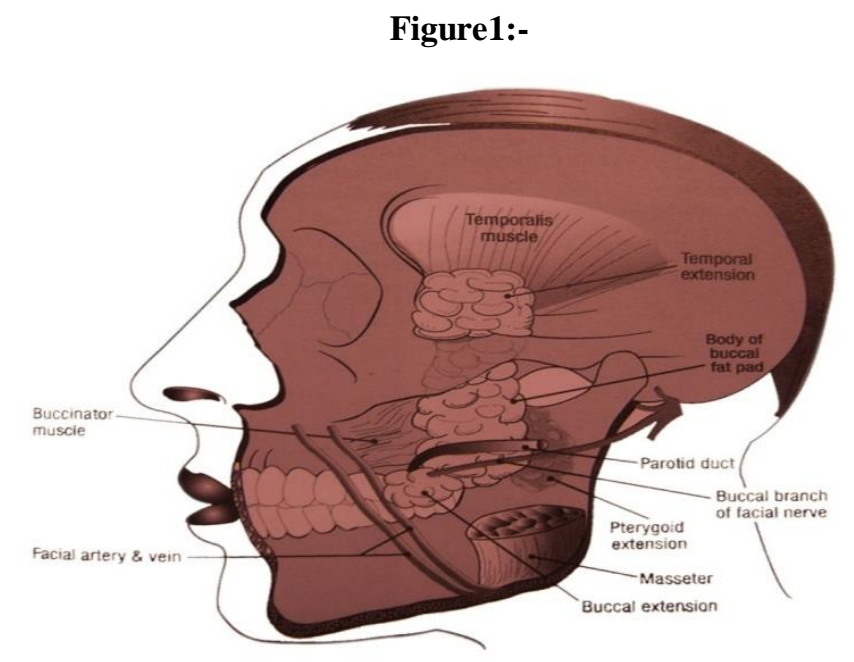

Figure 2 \& 3:-Reduced mouth opening

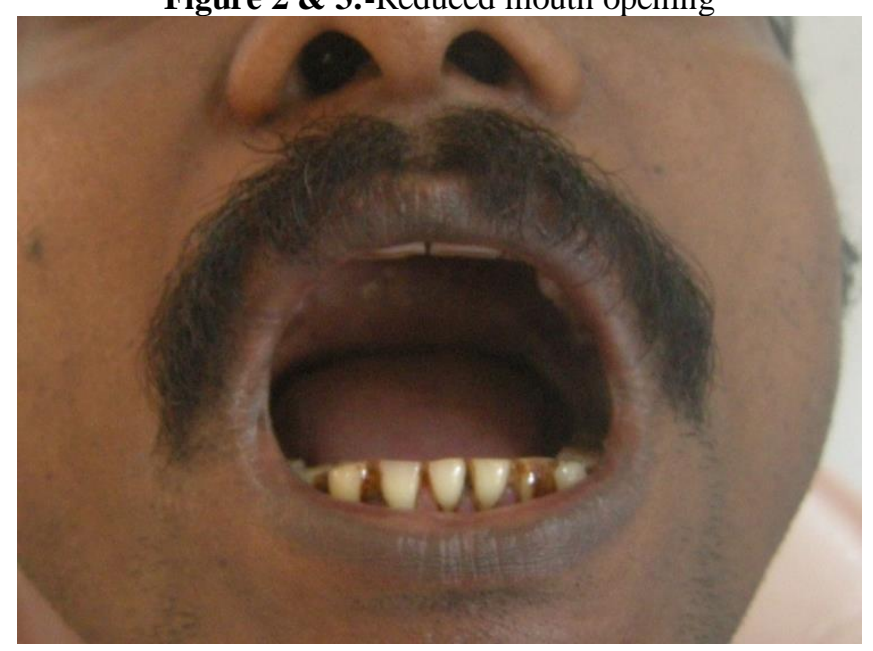


Figure 3:-Measuring mouh opening

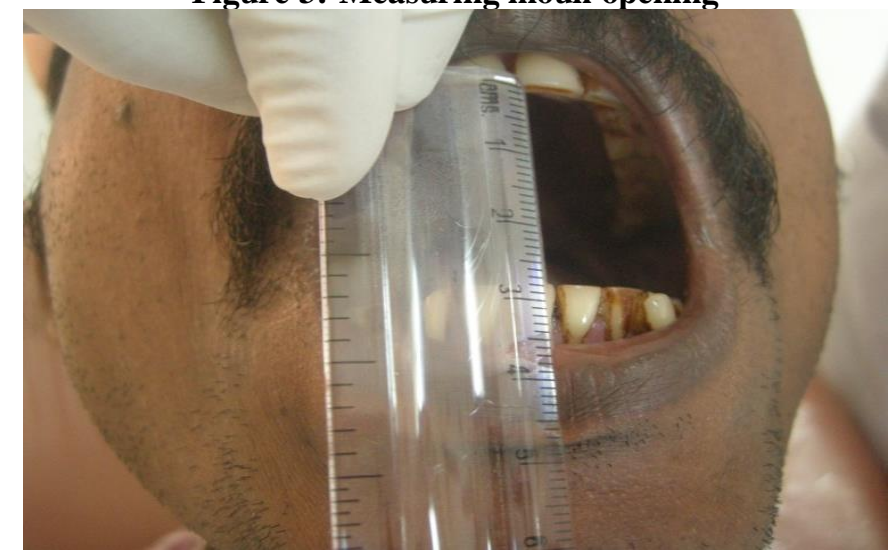

Figure 4:-Intra oral view showing deformed uvula

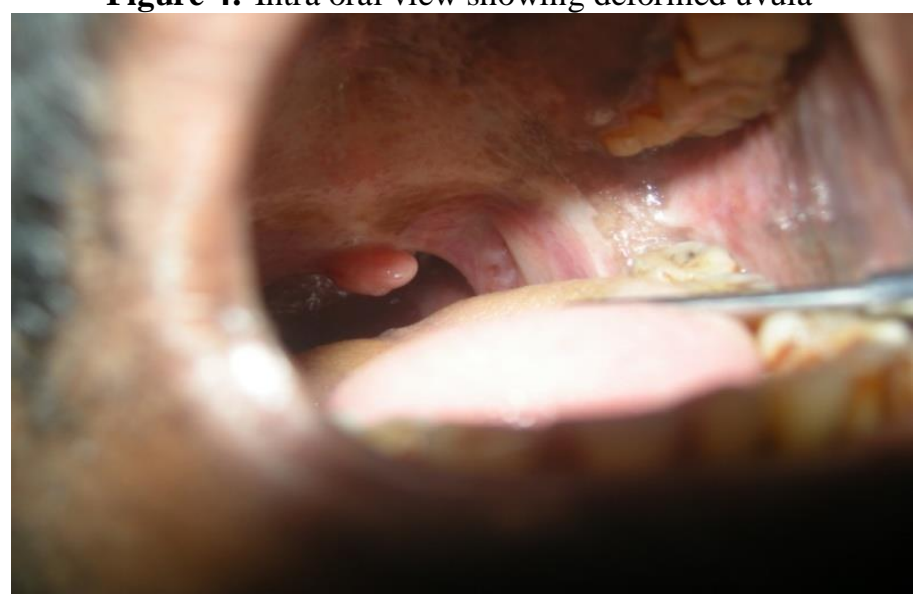

Figure 5:-Surgical excision of lesion in left buccal mucosa

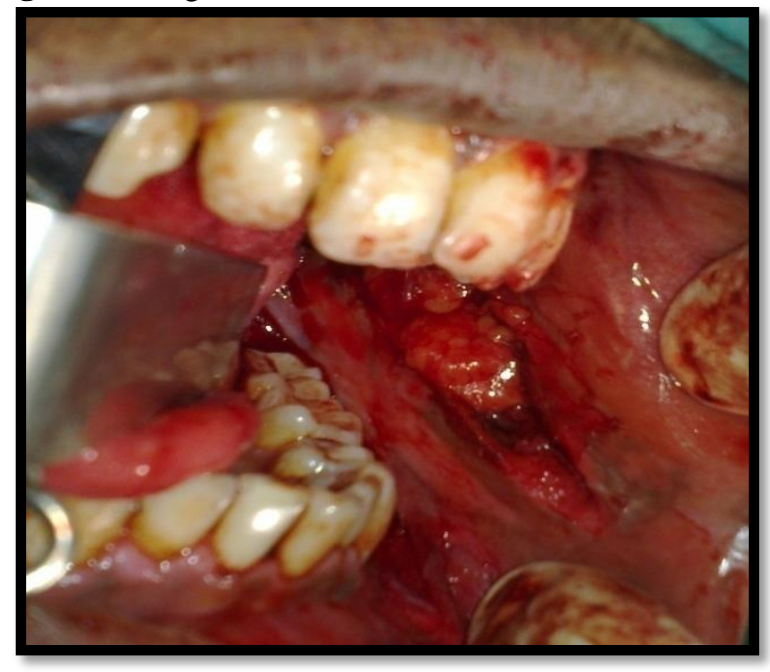


Figure 6:-Mobilisation of buccal pad of fat.

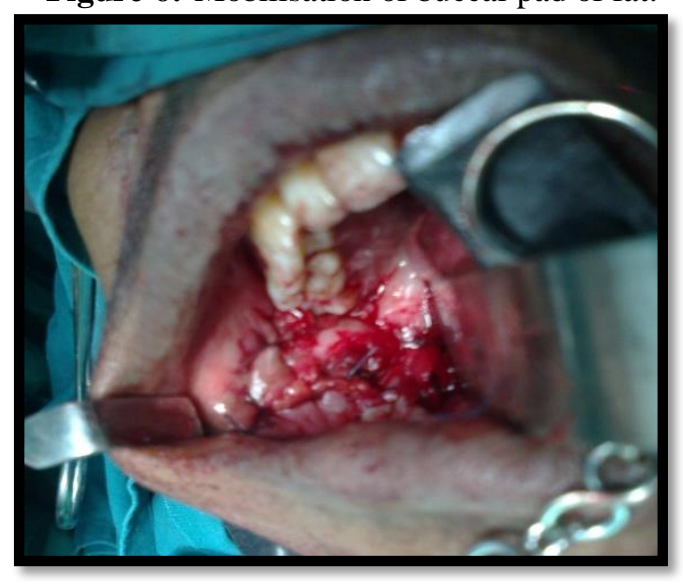

Figure 7:-Post Operative view after 1 month

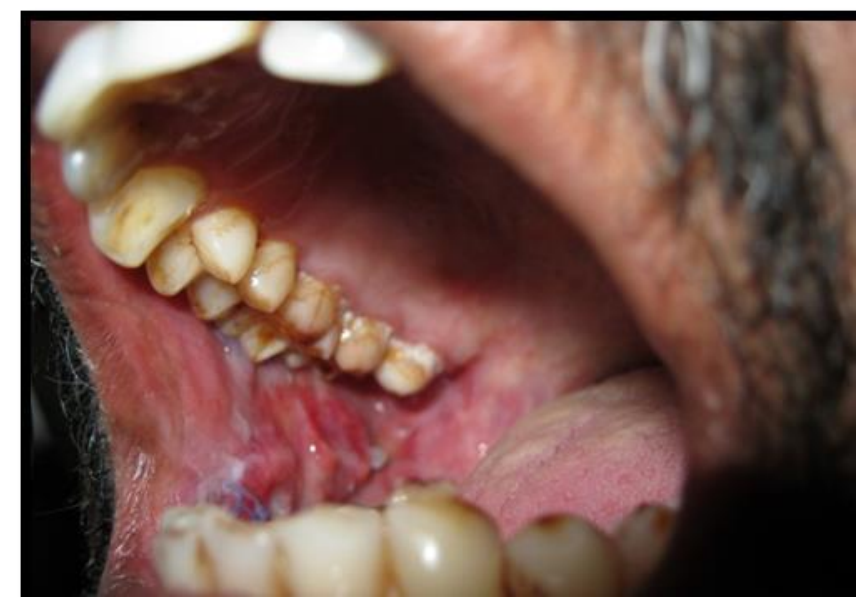

\section{References:-}

1. Pindborg J, Sirsat S. Oral submucous fibrosis. Oral Surgery, Oral Medicine, And Oral Pathology 1966;22(6):764. 3. Rajendran R. Oral submucous fibrosis: etiology, pathogenesis, and future research. Bulletin of the World Health Organization 1994;72(6):985-96

2. Gupta SC. "Mist" an aetiological factor in oral submucosal fibrosis. IndianJ Otolaryngology 1978;30(1):5-6.

3. Sabharwal R, Gupta S, Kapoor K, Puri A, Rajpal K. Oral Submucous Fibrosis- A Review. J Adv Med Dent Scie Res 2013;1(1):29-37.

4. Gupte, et al: : AutogenousBuccal Fat Pad in the Treatment of Oral Submucous Fibrosis. International Journal of Scientific Study 2014; 6(1).

5. Morawetz G, Katsikeris N, Weinberg S, et al: Oral submucous fibrosis. Int J Oral MaxillofacSurg 1987;16:609.

6. K. Saravanan ,VinodNarayanan.The Use of Buccal Fat Pad in the Treatment of Oral Submucous Fibrosis: A Newer Method. International Journal of DentistryVolume 2012.

7. Syed Ansar Ahmad, Saif Khan, Mohd. Sami Ahmad. Buccal fat pad reconstruction of oral mucosa in leukoplakiaOzean Journal of Medical Sciences 2010;1(1).

8. M. A. Amin, B. M. W. Bailey, B. Swinson, and H. Witherow, "Use of the buccal fat pad in the reconstruction and prosthetic rehabilitation of oncological maxillary defects," British Journalof Oral and Maxillofacial Surgery 2005; 43(2): 148-154.

9. A. Baumann and R. Ewers, "Application of the buccal fat pad in oral reconstruction," Journal of Oral and MaxillofacialSurgery2000; 58(4), 389-392.

10. Egyedi P. Utilisation of the buccal fat pad for closure oforo-antral and/or oro-nasal communications. $\mathbf{J}$ Maxillofac Surg1977;5:241-4.

11. Neder A. Use of buccal fat pad for grafts. Oral Surg Oral Med Oral RadiolEndod 1983;55:349-50. 
12. Martin-Granizo R, Naval L, Costas A, Goizueta C, Rodriguez F, Monje F, et al. Use of buccal fat pad to repair intraoral defects: review of 30 cases. Br J Oral MaxillofacSurg 1997;35: 81-4.

13. Dubin B, Jackson IT, Halim A, Triplett WW, Ferreira M. Anatomy of the buccal fat pad and its clinical significance. PlastReconstrSurg 1989;82:257-64.

14. Hao SP. Reconstruction of oral defects with the pedicledbuccal fat pad flap. Otolaryngol Head Neck Surg 2000;122:863-7.

15. Stuzin JM, Wagstrom L, Kawamoto HK, Baker TJ, Wolfe SA.The anatomy and clinical applications of the buccal fat pad. PlastReconstrSurg 1990;85:29-37.

16. Samman N, Cheung LK, Tideman H. The buccal fat pad in oral reconstruction. Int J Oral MaxillofacSurg 1993;22:2-6.

17. Seedat HA, van Wyk CW. Betel-nut chewing and submucous fibrosis in Durban. S Afr Med J. Dec 3 1988;74(11):568-71.

18. Shevale V, Kalra R, Shringarpure M. Management of Oral Sub-MucousFibrosis: A Review. Indian Journal of Dental Sciences.2012; 4 (2); 107-114.

19. Borle RM, Borle SR: Management of oral submucous fibrosis: A conservative approach. J Oral MaxillofacSurg 1991;49:788,

20. El-Hakim IE, El-Fakharany AM. The use of pedicledbuccal fat pad and palatal rotating flaps in closure of oroantral communication and palatal defects. J LaryngolOtol 1999;113:834-8.

21. Borle RM, Nimonkar PV, Rajan R: Extended nasolabial flaps in the management of oral submucous fibrosis. $\mathrm{Br}$ J Oral MaxillofacSurg 2009; 47:382.

22. Khanna JN, Andrade NN: Oral submucous fibrosis: A new concept in surgical management. Report of 100 cases. Int J Oral Maxillofac Surg1995; 24:433.

23. Wei FC, Chang YM, Kildal M, et al: Bilateral small radial forearm flaps for the reconstruction of buccal mucosa after surgical release of submucosal fibrosis: A new reliable approach. PlastReconstr Surg2001;107:1679.

24. Lee J-T, Cheng L-F, Chen P-R, et al: Bipaddled radial forearm flap for the reconstruction of bilateral buccal defects in oral submucous fibrosis. Int J Oral MaxillofacSurg 2007;36:615.

25. Rapidis AD, Alexandridis CA, Eleftheriadis E, Angelopoulos AP. The use of the buccal fat pad for reconstruction of oral defects: review of the literature and report of 15 cases. J Oral MaxillofacSurg 2000;58:158-63.

26. Martin-Granizo R, Naval L, Costas A, Goizueta C, Rodriguez F, Monje F, et al. Use of buccal fat pad to repair intraoral defects: review of 30 cases. Br J Oral MaxillofacSurg 1997;35: 81-4.

27. GunjanShrivastava, SubratPadhiary, HarshmohanPathak, Swagatika Panda, ShitaprajnaLenka. Buccal fat pad to repair intraoral defects .International Journal of Scientific and Research Publications February 2013; 3(2). 